\title{
Zur Beweiskraft von Traditionsnotizen im österreichischen Raum
}

\section{The power of evidence in traditiones from Austria}

Roman Zehetmayer / Roman.Zehetmayer@noel.gv.at

Niederösterreichisches Landesarchiv, St. Pölten

\begin{abstract}
In recent years, traditiones were often characterised as "party-neutral authentications" with legal power. But there are arguments against this view, since noblemen tended to register legal acts only occasionally within monastic traditiones. Apparently, they didn't assign them any official credibility. There is also no proof that traditiones were recognised as legal evidence in court. More likely, they were considered as memory aid in oral contracts, even when the notoriousness could guarantee the legal continuity in excess of the witnesses proof.
\end{abstract}

\section{Keywords}

Traditiones, conclusiveness, legal continuity, evidence, charter evidence, notoriety, party-neutral authentication, witness proof, forgery of instruments, private sealed charters 
Angesichts des eher bescheidenen Stellenwerts der Diplomatik in der Geschichtsforschung der letzten Jahrzehnte wundert es nicht, dass sich auch die Zahl der Debatten um diplomatische Themen in Grenzen gehalten hat - die auf der Tagung in Brno diskutierte Frage, ob in Urkunden eher ein Rechtsinstrument oder ein Mittel der symbolischen Kommunikation bzw. der Memorialpflege zu sehen ist, stellt da eher eine Ausnahme dar. Bei österreichischen und bayerischen Diplomatikern wurde in den letzten Jahrzehnten indes doch auch noch ein anderes, damit aber irgendwie auch wieder zusammenhängendes Problem zuweilen intensiv erörtert, nämlich ob denn Traditionsnotizen eine öffentlich anerkannte Rechts- bzw. Beweiskraft zugekommen ist oder nicht. Da diese Diskussion noch immer nicht zu einem Konsens geführt hat, ${ }^{1}$ soll sie hier noch einmal aufgegriffen, aber auch der Versuch unternommen werden, einige bislang vielleicht weniger beachtete Facetten dazu beizusteuern.

Dass diese Frage gerade in Bayern und Österreich thematisiert wurde und wird, ist kein Zufall, kommen hier doch Traditionsnotizen bzw. Notitien ${ }^{2}$ am weitaus häufigsten vor und zählen im Hochmittelalter zu den wichtigsten Quellen überhaupt. ${ }^{3}$ Entstanden sind diese, indem grundsätzlich mündlich geschlossene Rechtsgeschäfte meist unter Einhaltung gewisser urkundlicher Formen auf Einzelzettel schriftlich festgehalten wurden, ${ }^{4}$ die früher oder später der besseren Übersichtlichkeit halber, und um eine Sicherheitskopie zu erhalten, in Kodizes, häufig in so genannte Traditionsbücher, kopiert wurden. ${ }^{5}$ Erhalten geblieben sind fast immer nur alleine diese Traditionsbücher, während kaum je eine Einzelnotiz bzw. -notitia die Zeiten überdauert hat. Traditionsnotizen wurden fast ausschließlich von den vom Rechtsgeschäft betroffenen geistlichen Institutionen niedergeschrieben, ganz selten ließen auch Adelige ihre mündlich geschlossenen Verträge schriftlich aufzeichnen. Das bekannteste Beispiel ist der so genannte Codex Falkensteinensis, eine auf Veranlassung des bayerisch-österreichischen Grafen Siboto von Falkenstein um 1170 entstandene Handschrift, in die auch dessen zahlreichen Rechtsgeschäfte in Form von Traditionsnotizen eingetragen wurden. ${ }^{6}$

$1 \quad$ Siehe dazu Anm. 78.

2 Eine Definition von Traditionsnotizen zuletzt bei Härtel, Reinhard: Notarielle und kirchliche Urkunden im frühen und hohen Mittelalter. Wien - München 2011, S. 109.

3 Siehe die Überblicke bei Widemann, Josef: Die Traditionen bayerischer Klöster. Zeitschrift für bayerische Landesgeschichte 1, 1928, S. 225-243; Mitis, Oskar: Studien zum älteren österreichischen Urkundenwesen. Wien 1912, S. 38-45; Dienst, Heide: Babenberger-Studien. Niederösterreichische Traditionsnotizen als Quellen für die Zeit Markgraf Leopolds III. Wiener Dissertationen aus dem Gebiete der Geschichte 7. Wien 1966, S. 5-16.

4 Siehe allgemein zum Aussehen der Traditionszettel Johanek, Peter: Zur rechtlichen Funktion von Traditionsnotiz, Traditionsbuch und früher Siegelurkunde. In: Recht und Schrift im Mittelalter. Hg. von P. Classen. Vorträge und Forschungen 23. Sigmaringen 1977, S. 131-162, hier S. 145f. Die Frage, ob bei der Rechtshandlung bereits erste Notizen über die beteiligten Personen und den Sachverhalt angefertigt und erst im Kloster oder den Bischofssitzen ausformulierte Traditionsnotizen niedergeschrieben worden sind, kann hier bei Seite gelassen werden.

5 Dienst, Heide: Regionalgeschichte und Gesellschaft im Hochmittelalter am Beispiel Österreichs. Mitteilungen des Instituts für Österreichische Geschichtsforschung (= MIÖG), Ergänzungsband 27. Wien - Köln 1990, S. 106f., 115f.; Wanderwitz, Heinrich: Traditionsbücher bayerischer Klöster und Stifte. Archiv für Diplomatik 24, 1978, S. 359-380.

6 Druck: Codex Falkensteinensis. Die Rechtsaufzeichnungen der Grafen von Falkenstein. Ed. E. Noichl. Quellen 
$* * *$

Die ersten, die sich intensiv mit Traditionsnotizen und deren Rechtskraft auseinandergesetzt haben, waren um 1900 Oswald Redlich ${ }^{7}$ und Oskar Mitis ${ }^{8}$, die auf den Ergebnissen Heinrich Brunners zur Rechtsgeschichte der Urkunde aufbauend ${ }^{9}$ Traditionsnotizen an sich keine Beweiskraft zubilligten. Diese beruhe nach Redlich und Mitis alleine auf den Aussagen der Zeugen, weshalb es die wichtigste Funktion der Traditionsnotiz gewesen sei, jene und den Rechtsinhalt schriftlich festzuhalten. ${ }^{10}$ Dies komme auch in einigen der selten vorhandenen Corroborationes von Traditionsnotizen zum Ausdruck, in denen ausdrücklich die Zeugen als Rechtsgaranten für den geschlossenen Vertrag gesehen werden. ${ }^{11}$ Ergänzt kann werden, dass dabei zuweilen das Heranziehen von Zeugen sogar ausdrücklich als gültiges Recht bezeichnet wird. ${ }^{12}$ Es lassen sich auch zahlreiche Beispiele dafür finden, dass im Streitfall vor Gericht Zeugen befragt wurden und diese zur Entscheidungsfindung beitrugen. ${ }^{13}$

und Erörterungen zur bayerischen Geschichte N. F. 29. München 1978. Siehe etwa Johanek, P. Funktion, S. 153; Rösener, Werner: Codex Falkensteinensis. Zur Erinnerungskultur eines Adelsgeschlechts im Hochmittelalter. In: Adelige und bürgerliche Erinnerungskulturen des Spätmittelalters und der Frühen Neuzeit. Hg. von W. Rösener. Fomen der Erinnerung 8. Göttingen 2000, S. 35-55; Dienst, H.: Regionalgeschichte, 124f.; Zehetmayer, Roman: Urkunde und Adel. Ein Beitrag zur Geschichte der Schriftlichkeit im Südosten des Reichs vom 11. bis zu frühen 14. Jahrhundert. Veröffentlichungen des Instituts für Österreichische Geschichtsforschung 53. Wien - München 2010, S. 26-33.

7 Redlich, Oswald: Über bairische Traditionsbücher und Traditionen. MIÖG 5, 1884, S. 1-82; Ders.: Die Privaturkunden des Mittelalters. Handbuch der mittelalterlichen und neueren Geschichte IV/3. München - Berlin 1911, S. 68-92.

8 Mitis, O.: Urkundenwesen, S. 5-64.

9 Brunner, Heinrich: Carta und Notitia. Ein Beitrag zur Rechtsgeschichte der germanischen Urkunde. In: Commentationes philologae in honorem Theodori Mommsen. Berlin 1877, S. 570-589; Nachdruck in: Abhandlungen zur Rechtsgeschichte. Gesammelte Aufsätze von Heinrich Brunner 1. Hg. von K. Rauch. Weimar 1931, S. 458-486.

10 Redlich, O.: Traditionsbücher, S. 60f.; Ders.: Privaturkunden, S. 69; siehe auch Ders.: Geschäftsurkunde und Beweisurkunde. MIÖG, Ergänzungsband 6. Innsbruck 1901, S. 1-16, hier S. 1; Mitis, O.: Urkundenwesen, S. 4-6 und passim; siehe dazu auch Dienst, H.: Regionalgeschichte, S. 110f.: „Redlichs aufgrund ausgedehnter Materialstudien gewonnener Meinung, Traditionsbücher seien in erster Linie als Gedächtnisstützen, nicht als Beweismittel vor Gericht angelegt worden, kann im Grunde nicht wirklich widersprochen werden".

11 Mitis, O.; Urkundenwesen, S. 26; Redlich, O.: Privaturkunden, S. 75; weitere Beispiele bei Zehetmayer, R.: Urkunde, S. 58; Mell, Richard: Beiträge zur Geschichte der steirischen Privaturkunde. Forschungen zur Verfassungs- und Verwaltungsgeschichte der Steiermark 8/1. Graz - Wien 1911, S. 78.

12 Etwa Salzburger Urkundenbuch. Bd. I. Traditionscodices. Ed. W. Hauthaler. Salzburg 1898, S. 240 Nr. 19: Et istis testibus utramque traditionem legali more confirmantibus; Urkundenbuch des Landes ob der Enns I. Wien 1851, S. 306, Nr. 60: testibus consueto more tractis subnotatis et conscriptis; siehe auch den Brief Gerhochs von Reichersberg ebd. S. 313, Nr. 69; Die Traditionsbücher des Benediktinerstiftes Göttweig. Ed. A. Fuchs. Fontes rerum Austriacarum II/69. Wien 1931, Nr. 267: idonei et necessarii testes; Codex traditionum ecclesiae collegiatae Claustroneoburgensis [...]. Ed. M. Fischer. Fontes rerum Austriacarum II/4. Wien 1851, S. 118-119, Nr. 542: testibus ex more notatis; ebd. S. 130-131, Nr. 581: testes ex more adducti sunt; Zehetmayer, R.: Urkunde, S. $58 \mathrm{f}$.

13 Siehe etwa die Beispiele bei Zehetmayer, R.: Urkunde, S. 59; siehe auch Härtel, Reinhard: Schrift und Gericht. In: Schriftkultur zwischen Donau und Adria bis zum 13. Jahrhundert. Akten der Akademie Friesach „Stadt und Kultur im Mittelalter“. Friesach (Kärnten), 11.-15. September 2002. Hg. von R. Härtel et al. Schriftenreihe der Akademie Friesach 8. Klagenfurt 2008, S. 363-397, hier S. 372; allgemein auch Clanchy, Michael: From Memory to Written Record. England 1066-1307. London 1993², S. 260-266. 
Redlich und Mitis haben sich auch bereits Gedanken über das zwangsläufig aus einer auf Zeugenbeweis beruhenden Rechtsfindung entstehende Problem gemacht, nämlich das der Sterblichkeit der Zeugen und die mangelnden Möglichkeiten, über deren Tod hinaus die Rechtskontinuität zu sichern. ${ }^{14}$ Vor allem Mitis wies in diesem Zusammenhang auf das Prinzip der Offenkundigkeit der Rechtshandlung ${ }^{15}$ und nachdrücklich darauf hin, dass ein Rechtsgeschäft öffentlich verlautbart werden musste und so auch weitere, nicht als Zeugen angeführte Personen darüber informiert wurden. Diese erzählten davon wiederum anderen, bei der Handlung gar nicht anwesenden Verwandten, Bekannten oder Nachbarn, so dass ein Sachverhalt einfach allgemein bekannt wurde, damit eben offenkundig bzw. landeskundig war. ${ }^{16}$

Noch wichtiger wurde das Prinzip der Offenkundigkeit für Heinrich Fichtenau in seiner 1971 erschienenen Monographie über das Urkundenwesen Österreichs. Er sah im öffentlichen Wissen geradezu die Grundvoraussetzung für die Gültigkeit eines Rechtsgeschäfts. Erst die Verlautbarung habe die notwendige Öffentlichkeit hergestellt. ${ }^{17} \mathrm{Er}$ ging noch einen Schritt weiter und meinte, dass die Traditionsnotiz "durch die schriftliche Niederlegung das Verlautbarte“ gleichsam „verewigt"18 und schon damit einem rechtlichen Zweck dient. ${ }^{19}$ „Das geschriebene Wort sprach“ nach Fichtenau „auch zu den Abwesenden, d.h. es konnte immer wieder hervorgeholt und gelesen werden “20. Fichtenau sah also in der Niederschrift nicht zuletzt ein Werkzeug, um Offenkundigkeit herzustellen, und hat Traditionsnotizen einen rechtssichernden Charakter zugebilligt. Wie er sich dies genau und konkret in der Rechtspraxis vorgestellt hat, bleibt freilich etwas unklar. Er dürfte aber nicht die Meinung vertreten haben, dass die Notitia oder

14 Mitis, O.: Urkundenwesen, S. 5f.; Redlich, O.: Privaturkunden S. 116. Siehe etwa bereits die bekannte Bemerkung im Schwabenspiegel, Kurzform. I. Landrecht. II. Lehnrecht. Ed. K. A. Eckhardt. Monumenta Germaniae Historica. Fontes iuris Germanici antiqui n. s. 4. Hannover 1974², Landrecht $§ 36$ a, S. 84: Wir sprechen, das brief pesser sint dann zewgen; wann gezeugen sterbent, so pleibent brief ymmer stat. Siehe dazu auch Trusen, Winfried: Zur Urkundenlehre der mittelalterlichen Jurisprudenz. In: Recht und Schrift im Mittelalter. Hg. von P. Classen. Vorträge und Forschungen 23. Sigmaringen 1977, S. 197-219, hier S. 209 und passim; Zehetmayer, R.: Urkunde, S. 56.

15 Mitis, O.: Urkundenwesen, S. 11f., 13; siehe auch Redlich, O.: Privaturkunden, S. 71. Dass nicht nur Handlungszeugen vor Gericht herangezogen werden konnten, war von der Rechtsgeschichte bereits zuvor erkannt worden; etwa Brunner, Heinrich: Deutsche Rechtsgeschichte 2. Bearb. von C. von Schwerin. Systematisches Handbuch der Deutschen Rechtswissenschaft II/1/2. Berlin 1928 2 , 107 . Siehe weiters Trusen, W.: Urkundenlehre, S. $204 \mathrm{f}$.

16 Was etwa durch den Vertragsabschluss bei sonntäglichen Gottesdiensten oder bei Landtaidingen gefördert wurde; Mitis, O.: Urkundenwesen, S. 12.

17 Fichtenau, Heinrich: Das Urkundenwesen in Österreich vom 8. bis zum frühen 13. Jahrhundert. MIÖG, Ergänzungsband 23. Wien - Köln - Graz 1971, S. 80.

18 Ebd. S. 137 (unter Anführungszeichen).

19 Ebd. Siehe auch Fichtenau, Heinrich: Forschungen über Urkundenformeln. Ein Bericht. MIÖG 94, 1986, S. 285-339, hier S. 306f.; Wanderwitz, H.: Traditionsbücher, S. 361.

20 Fichtenau, H.: Urkundenwesen, S. 137; siehe auch ebd. S. 138: „Es kann sein, daß die schriftliche Zeugenliste auch mehr bedeutete, etwa nach dem Tod aller Zeugen als eine gewisse Gewähr für die Richtigkeit der Sache angesehen wurde“. Siehe auch Sonnlechner, Christoph: Landschaft und Tradition. Aspekte einer Umweltgeschichte des Mittelalters. In: Text - Schrift - Codex. Quellenkundliche Arbeiten aus dem Institut für Österreichische Geschichtsforschung. Hg. von C. Egger - H. Weigl. MIÖG, Ergänzungsband 35 . Wien - München 2000, S. 123-223, hier S. 136. 
ein Traditionsbuch auch als Beweismittel vor Gericht anerkannt worden wäre, ${ }^{21}$ sondern dass die Niederschrift die Erinnerung und diese die Offenkundigkeit und damit eben in gewissem Sinne die Rechtskontinuität verlängern konnte.

Fichtenau hat weiter auf die immer wieder vorgenommene Niederschrift von Traditionsnotizen in liturgischen Texten hingewiesen, wodurch sie in eine religiöse Sphäre eingebunden wurden und auch so höhere rechtliche Anerkennung gefunden hätten. ${ }^{22}$

Diese neue Sichtweise Fichtenaus auf das Wesen der Traditionsnotizen übte auf die weitere Forschung einen großen Einfluss aus und führte zu weiteren Untersuchungen in diesem Sinne. Wichtige Studien dazu stammen nicht zuletzt von Peter Johanek, der in seiner Dissertation darauf hingewiesen hat, dass ein Streit zwischen einem Adeligen und einem Kloster in der Diözese Würzburg über eine ältere Schenkung durch den Bischof ex auctoritate testamenti super hoc descripti entschieden worden ist, wobei unter dem testamentum nach Johanek eine entsprechende ältere Traditionsnotiz gemeint sei. Hier läge demnach ein Beleg für die Anerkennung einer Traditionsnotiz als Beweismittel vor Gericht vor, was Johanek mit dem Schriftzauber erklärt hat, der hier den Laien überzeugt habe. ${ }^{23}$ In einer späteren Arbeit strich er vor allem die Bedeutung der Traditionsbücher als wichtige Trägermedien der Memoria heraus, weil diese Texte sehr häufig die Namen der Tradenten und die mit der Schenkung verbundenen Gebetsleistungen festgehalten hätten. ${ }^{24}$ Die Aufzeichnung der Schenkung kam einer Aufforderung zur Einlösung der Gegenleistung gleich, die in der Regel eben bestimmte Gebete und, damit verbunden, die Memoria an den Tradenten ausmachten. ${ }^{25}$ Dieser konnte sich darauf verlassen, dass bei Anfechtungen nach seinem Tode die beschenkte Kirche zur Erhaltung des tradierten

21 Zumindest äußert er sich offenbar nirgends eindeutig in diese Richtung. Siehe etwa Fichtenau, H.: Urkundenwesen, S. 79.

22 Fichtenau, H.: Urkundenwesen, S. 61, 82f. Siehe dazu auch Johanek, P.: Funktion, S. 146, 152; Dienst, H.: Regionalgeschichte, S. 107, wonach das Aufschreiben eines Namens auf einen Zettel für Analphabeten eine magische Handlung gewesen sei. Zum magischen Charakter der Schrift siehe etwa Hartung, Wolfgang: Die Magie des Geschriebenen. In: Schriftlichkeit im frühen Mittelalter. Hg. von U. Schaefer. ScripOralia 53. Tübingen 1993, S. 109-126; Mostert, Marco: Schrift, Wahrheit und Betrug im frühen und hohen Mittelalter. In: Schriftkultur zwischen Donau und Adria bis zum 13. Jahrhundert. Akten der Akademie Friesach „Stadt und Kultur im Mittelalter“. Friesach (Kärnten), 11.-15. September 2002. Hg. von R. Härtel et al. Schriftenreihe der Akademie Friesach 8. Klagenfurt 2008, S. 273-291, hier S. 280; Clanchy, M.: Memory, S. 35-43; zur angeblich magischen Wirkung von Urkunden Stieldorf, Andrea: Die Magie der Urkunden. Archiv für Diplomatik 55, 2009, S. 1-32.

23 Johanek, Peter: Die Frühzeit der Siegelurkunde im Bistum Würzburg. Quellen und Forschungen zur Geschichte des Bistums und Hochstifts Würzburg 21. Würzburg 1969, S. 291; siehe Urkundenbuch der Benediktiner-Abtei St. Stephan in Würzburg I. Edd. F. J. Bendel - F. Heidingsfelder - M. Kaufmann. Veröffentlichungen der Gesellschaft für fränkische Geschichte 3/1. Leipzig 1912, Nr. 192 (1169): Idem etenim predium defuncto sine heredibus Eberhardo filio ipsorum ex auctoritate testamenti super hoc descripti in ius et potestatem abbatis et fratrum devenerat, sed a quodam Sigebotone et filiis eius violenter invadebatur. Nos [der Bischof von Würzburg] vero iniusticie et iniquitati eorum resistentes, cum resipiscere detrectarent, in banno eos constituimus, donec tandem ex consilio amicorum utrarumque partium in hoc consensum est [...]. Siehe dazu unten S. 13.

24 Johanek, P.: Funktion, S. 145.

25 Siehe dazu ausführlich auch Sauer, Christine: Fundatio und Memoria. Stifter und Klöstergründer im Bild 1100 bis 1350. Veröffentlichungen des Max-Planck-Instituts für Geschichte 109. Göttingen 1993, S. 37-42. 
Gutes, aber auch im Interesse seines Seelenheils die genannten Zeugen aufbot. ${ }^{26}$ Die Memorialpflege war für den Tradenten ein Anreiz, einen Vertrag einzuhalten, da er sonst nicht auf die Gebetsleistungen hoffen konnte. Daran waren aber, was wohl noch wichtiger war, auch die Nachfahren des Stifters gebunden, da eine Anfechtung der Stiftung die Gebetsleistungen für den Verwandten in Frage gestellt hätte. ${ }^{27}$ Stephan Molitor meinte 1990 sogar, dass die allgemeine Wertschätzung, die auf diese Weise vor allem den Traditionskodizes als Trägern der Stiftermemoria zukam, dazu beitrug, dass diesen Dokumenten rechtssichernde Qualität unabhängig vom Zeugenbeweis zuerkannt wurde..$^{28}$

Weitere Argumente steuerte der bayerische Historiker Heinrich Wanderwitz bei, der 1978 darauf aufmerksam machte, dass Zensualen des Klosters Herrenchiemsee zur rechtlichen Sicherung des Dienstverhältnisses darum baten, namentlich in ein Traditionsbuch eingetragen zu werden, ${ }^{29}$ und ein Garstener Traditionsbuch im Jahre 1233 als authenticum [...] registrum bezeichnet wurde. ${ }^{30} \mathrm{Er}$ folgert daraus, dass „in einer Zeit, in der sich die Siegelurkunde immer mehr durchsetzte, [...] der unbesiegelte Traditionsbucheintrag, [...], der Siegelurkunde praktisch gleichgestellt“ wurde ${ }^{31}$ und Traditionsbücher in Bayern und Österreich überhaupt öffentliche Anerkennung gefunden hätten und rechtserheblich gewesen wären. ${ }^{32}$

Schritt für Schritt wurde also die Rechtskraft der Traditionsnotizen und Traditionsbücher immer höher bewertet. Es gab allerdings auch Stimmen, denen dies zu weit ging. So legte Heide Dienst im Jahre 1990 als Reaktion auf die Ausführungen von Wanderwitz en passant dar, dass die Zumessung von Beweiskraft eher dem Wunschdenken der Mönche als der Realität entsprochen habe. Sie hält aber fest, dass die Eintragung in ein Buch die Rechtssicherheit eines Vertrags erhöhen konnte. ${ }^{33}$ Dienst betont weiter die Bedeutung der Einzelnotitien an sich als Übergabesymbol. ${ }^{34}$ So sei etwa die Übertragung von Zensualen an eine geistliche Institution mit der gleichzeitigen Übergabe eines die Namen der geschenkten Personen enthaltenden Zettels verknüpft gewesen, der die Funk-

26 Johanek, P.: Funktion, S. 145; Sauer, C.: Fundatio, S. 38f.

27 Johanek, P.: Funktion, S. 145; siehe auch Johanek, Peter: Die Corveyer Traditionen als Gedenküberlieferung. In: Der Liber Vitae der Abtei Corvey. Studien zur Corveyer Gedenküberlieferung und zur Erschließung des Liber Vitae. Hg. von K. Schmid - J. Wollasch. Veröffentlichungen der Historischen Kommission für Westfalen 40/2/2. Wiesbaden 1989, S. 124-134, hier S. 128; Sonnlechner, C.: Landschaft, S. 138.

28 Molitor, Stephan: Das Traditionsbuch. Zur Forschungsgeschichte einer Quellengattung und zu einem Beispiel aus Südwestdeutschland. Archiv für Diplomatik 36, 1990, S. 61-92, hier S. 85; siehe auch Sauer, C.: Fundatio, S. $40 \mathrm{f}$.

29 Wanderwitz, H.: Traditionsbücher, S. 375; siehe Zehetmayer, R.: Urkunde, S. 65.

30 Wanderwitz, H.: Traditionsbücher, S. 376; siehe dazu bereits Mitis, O.: Urkundenwesen, S. 64. Überlegungen, welches Garstener Traditionsbuch im Revers von 1233 als authenticum registrum bezeichnet wurde, finden sich bei Haider, Siegfried: Studien zu den Traditionsbüchern des Klosters Garsten. MIÖG, Ergänzungsband 52. Wien - München 2008, S. 140.

31 Wanderwitz, H.: Traditionsbücher, S. 376f.

32 Ebd. S. 378.

33 Dienst, H.: Regionalgeschichte, S. 106, 111; siehe auch Sonnlechner, C.: Landschaft, S. 136, der sich zunächst zwar Wanderwitz anschließt, dann aber unvermittelt auch die Meinung Heide Dienst vorbringt. 
tion eines Übergabesymbols erhielt. Dies gelte auch bei Liegenschaftsübertragungen, bei denen statt einer Frucht oder eines Zweigs die Zettel selbst symbolisch für das Gut übergeben, vielfach sogar auf dem Altar und damit auf den Reliquien eines Heiligen niedergelegt wurden. ${ }^{35}$ Weiter noch ging Hagen Keller, der die Meinung vertrat, dass ein Schriftstück als Investitursymbol „in eine rechtsbegründende Kette von öffentlichen Symbolhandlungen“ eingebaut war, wodurch „Verbindlichkeit und dauerhafte Geltung im kollektiven Gedächtnis “ hergestellt wurden. ${ }^{36}$

Am weitesten aber ging Joachim Wild, der ausgehend von der Bedeutung der Offenkundigkeit für die Rechtssicherheit und den objektiv gehaltenen Formulierungen der Traditionsnotizen, die nach Wild „allen Anschein von Parteiaufzeichnungen zu vermeiden such[ten]“, den die Traditionsnotizen aufzeichnenden Klöstern sogar die Aufgabe einer gleichsam „amtlichen Beurkundungsstelle“ zumessen will ${ }^{37}$ und meint, Traditionsnotizen seien als „objektive, parteineutrale Beurkundungen“ mit Rechtskraft anzusehen. ${ }^{38}$ Als Belege bringt er eine Tegernseer Traditionsnotiz aus der ersten Hälfte des 13. Jahrhunderts mit der Corroboratio Allegata sunt hec coram [...] abbate et sigillo sancti Quiri$n i^{39}$ und eine erhaltene Originalnotiz aus Prüfening aus dem 12. Jahrhundert vor, worin der Tradent den Abt bittet, das Rechtsgeschäft durch Niederschrift allegari. ${ }^{40}$ Durch die Verwendung des Verbs „allegare“ will Wild hierbei eine so genannte Allegation und eine Parallele zu den Gesta municipalia der Spätantike und des Frühmittelalters erkennen, ${ }^{41}$ als eine solche Allegation die Vereinbarung zwischen den Geschäftspartnern bedeutet habe, einen Vertrag in die Gesta municipalia, also einem von einer Behörde oder

35 Ebd. Weitere Literatur zu dieser Überlegung bei Zehetmayer, R.: Urkunde, S. 70.

36 Etwa Keller, Hagen: Schriftgebrauch und Symbolhandeln in der öffentlichen Kommunikation. Aspekte des gesellschaftlich-kulturellen Wandels vom 5. bis zum 13. Jahrhundert. Frühmittelalterliche Studien 37, 2003, S. 1-24, hier S. 13.

37 Wild, Joachim: Besiegelte Traditionsnotizen. In: Festschrift Walter Jaroschka zum 65. Geburtstag. Hg. von von A. Liess - H. Rumschöttel - B. Uhl. Archivalische Zeitschrift N. F. 80. München 1997, S. 469-483, hier S. 475, 477; Wild, Joachim: Charta und Notitia im Herzogtum Bayern. In: De litteris, manuscriptis, inscriptionibus ... Festschrift zum 65. Geburtstag von Walter Koch. Hg. von T. Kölzer et al. Wien - Köln - Weimar 2007, S. 27-37, hier S. 36; Ders.: Das Aufkommen der Siegelurkunde bei den bayerischen Klöstern. In: Auxilia Historica. Festschrift für Peter Acht zum 90. Geburtstag. Hg. von W. Koch - A. Schmid - W. Volkert. Schriftenreihe zur bayerischen Landesgeschichte 132. München 2001, S. 461-477, hier S. 464.

Wild, J.: Traditionsnotizen, S. 477f., 482. Die Zeugenlisten hatten laut Wild dagegen eher eine untergeordnete Funktion: „Daß die Nennung der Zeugen im Anfechtungsfalle die Beweisführung erleichtern sollte, indem man die Namen der Zeugen rasch bei der Hand hatte, ist sicherlich auch intendiert gewesen und war zumindest ein praktischer Nebeneffekt“; ebd. S. 478f. An die Stelle der Originalnotizen konnte nach Wild der Eintrag in das Traditionsbuch treten, das sich schließlich zu einem Auslaufregister für Siegelurkunden wandelte; Wild, J.: Charta, S. 37.

39 Bayerisches Hauptstaatsarchiv München, Best. Kloster Tegernsee, Sg. Urkunde Nr. 18.

40 Monumenta Boica 13. München 1777, S. 148, Nr. 3.

41 Siehe dazu auch bereits Fichtenau, H.: Urkundenwesen, S. 78-80. Fichtenau weist hier auf Analogien zwischen „der Tätigkeit der städtischen Magistrate und jener kirchlicher Behörden“ (S. 78) und in diesem Zusammenhang auf die Formulae Andecavenses des 6. Jahrhunderts hin. Auch vergleicht er die Notitia der Karolingerzeit mit der Funktion der Gesta municipalia und erkennt Ähnlichkeiten; siehe dazu auch Johanek, P.: Funktion, S. 144f. Allgemein Barbier, Josiane: Archives oubliées du haut Moyen Âge. Les gesta municipalia en Gaule franque (VI $-I X^{e}$ siècle). Histiore et archives 12. Paris 2014. 
anderen Autorität geführten allgemein anerkannten Buch mit notariellem Charakter, eintragen zu lassen. ${ }^{42}$

Die Thesen Wilds wurden in Bayern zustimmend, ${ }^{43}$ in Österreich eher gemischt aufgenommen. ${ }^{44}$ Beigepflichtet hat ihm hier vor allem Siegfried Haider im Zuge seiner Untersuchungen zu den Garstener Traditionskodizes, der beobachtete, dass in einem Fall tatsächlich ein Adeliger sein mit einer anderen geistlichen Institution geschlossenes Rechtsgeschäft in ein Traditionsbuch des Stiftes Garsten hat eintragen lassen, was er als Beleg für deren parteineutralen, öffentlichen Charakter wertete. ${ }^{45}$

Denkt man dies noch einmal durch und über die Beweiskraft der Traditionsnotizen noch einmal nach, so ergeben sich doch Fragen, so etwa wenn man die Perspektive

42 Wild, J.: Traditionsnotizen, S. 477f., das Zitat ebd. S. 478 mit Rückgriff auf Faussner, Hans Constantin: Zur Liegenschaftsübertragung in der Baioaria Provincia. Verfahrensrechtliche Kontinuität im bairischen Rechtsgebiet. Zeitschrift für Rechtsgeschichte (= ZRG). Germanistische Abteilung 111, 1994, S. 1-65, hier S. 6; siehe weiter Wild, J.: Traditionsnotizen, S. 482f.; Wild, J.: Wurzeln und Entwicklungslinien der privaten Siegelurkunde in Bayern (ca. 1150-1250). MIÖG 116, 2008, S. 235-248, hier S. 245; weiters Wild, J.: Aufkommen, S. 475f., mit der Interpretation einer Urkunde des Augustinerchorherrenstifts Rohr aus dem Jahre 1231, in der nach Wild die Aufgabe des Traditionsbuchs programmatisch zum Ausdruck gebracht worden sei: Volentes igitur omnia gesta nostra ad successorum nostrorum noticiam pervenire omnes contractus nostros in emptionibus, vendicionibus et concambiis, vel quibuscumque modis a nobis studiosius sunt peracti, presenti pagine duximus inserendos, singulos a quibus et cum quibus, quibus presentibus et procurantibus sunt fideliter pertractati, cum subscriptione testium studuimus annotare; Die Traditionen, die Urkunden und das älteste Urbarfragment des Stiftes Rohr 1133-1332. Ed. H.-P. Mai. Quellen und Erörterungen zur bayerischen Geschichte N. F. 21. München 1966, Nr. 107. Bemerkenswert erscheint hier die Mitteilung, dass den Nachfolgern im Kloster von den Rechtsgeschäften durch schriftliche Aufzeichnung Kenntnis vermittelt werden soll. Ob sich bei Konflikten Adelige durch die Vorlage des Traditionsbuches vor Gericht tatsächlich beeindrucken ließen, muss freilich auch in diesem Fall offen bleiben. Auffallend bleibt zudem, dass auch die Aufzeichnung der Zeugen als wichtig angeführt wurde; siehe Zehetmayer, R.: Urkunde, S. 66, Note 381. Siehe zur Funktion der Vorreden von Traditionsbüchern unten S. 16f.

43 Siehe etwa Die Traditionen des Augustiner-Chorherrenstifts Herrenchiemsee. Ed. B. Gilcher. Quellen und Erörterungen zur bayerischen Geschichte N. F. 49/1. München 2011, S. 86*f.; Die Regesten der Herzöge von Bayern 1180-1231. Ed. G. Schlütter-Schindler. Regesten zur bayerischen Geschichte. München 2013, S. IX mit Anm. 4.

44 Zustimmend Tiroler Urkundenbuch II/1: Bis zum Jahr 1140. Edd. M. Bitschnau - H. Obermair. Innsbruck 2009, S. XI Anm. 13; siehe dagegen Hecht, Alexander: Überlegungen zu einem hochmittelalterlichen Traditionsbuch. Der Liber delegacionum aus Reichersberg am Inn. In: Text - Schrift - Codex. Quellenkundliche Arbeiten aus dem Institut für Österreichische Geschichtsforschung. Hg. von C. Egger - H. Weigl. MIÖG, Ergänzungsband 35. Wien - München 2000, S. 91-122, hier S. 111, der die rechtliche Beweiskraft von Traditionsnotizen bezweifelt, hier aber nicht auf Wild eingeht, den er nur in einem anderen Zusammenhang zitiert (ebd. S. 106, Note 105), sondern sich gegen (hier nicht weiter auszuführende) Thesen Heinrich Kollers über die Beweiskraft von Traditionsnotizen ausspricht; Koller, Heinrich: Zur Anerkennung bayerischer Traditionsnotizen durch die Kurie. Archivalische Zeitschrift N. F. 75, 1979, S. 102-116; siehe dazu auch Zehetmayer, R.: Urkunde, S. 74f.

45 Haider, S.: Studien, S. 89, 165; Ders.: Die Streitfälle des Klosters Garsten um tradierte Güter. Lebensordnungen im Spiegel von Traditionsnotizen. In: Urkunden - Schriften - Lebensordnungen. Neue Beiträge zur Mediävistik. Hg. von A. Schwarcz - K. Kaska. Veröffentlichungen des Instituts für Österreichische Geschichtsforschung 63. Wien 2015, S. 213-228, hier S. 221-223. 
einer wesentlich betroffenen Schicht, nämlich des Adels, ins Kalkül zieht. ${ }^{46}$ So wird etwa nicht so recht klar, warum eigentlich Adelige ihre untereinander geschlossenen Rechtsgeschäfte nur ganz vereinzelt und eben nicht in größerer Zahl in klösterliche Traditionsbücher haben eintragen lassen, falls diesen - wie Wild voraussetzt - eine gleichsam amtliche Glaubwürdigkeit zukomme und die Adeligen so die Rechtssicherheit ihrer Verträge entscheidend erhöht und vor allem über Generationen hinweg verlängert hätten, ohne den Tod der Zeugen befürchten zu müssen. ${ }^{47}$

Auch gibt es Anhaltspunkte, dass Adelige Klöster nicht als neutrale Orte angesehen haben, finden sich doch in den Quellen nicht wenige Hinweise auf handfeste Konflikte zwischen Klöstern und Adeligen auch über frühere Schenkungen und zwar auch häufig zwischen Familien und diesen besonders nahe stehenden Konventen, was oft mit der Vogteiproblematik zu tun hat. ${ }^{48}$ Dass sich der Adel alleine auf die Niederschrift des Rechtsgeschäfts durch ein Kloster, das ja in den meisten Fällen der Vertragspartner mit eigenen Interessen war, verlassen hätte, wäre doch etwas verwunderlich. Selbst die wenigen bekannten Einträge adeliger Rechtsgeschäfte in Traditionsbücher unbeteiligter Klöster lassen sich in der Regel anders erklären und haben nichts mit der Anerkennung einer objektiven Beweiskraft zu tun. ${ }^{49}$

Entscheidend in der Frage nach der Beweiskraft der Traditionsnotizen ist aber wohl, ob diese tatsächlich auch vor Gericht Anerkennung gefunden haben. ${ }^{50}$ Wild selbst hat dazu kein Beispiel beigesteuert, wie erwähnt aber Peter Johanek in seiner Dissertation, in der er auf einen Streit zwischen einem Adeligen und einem Kloster der Diözese Würzburg über eine ältere Schenkung hingewiesen hat, der durch den Bischof ex auctoritate testamenti super hoc descripti entschieden worden ist, wobei unter dem testamentum eine entsprechende ältere Traditionsnotiz gemeint ist. ${ }^{51}$ Sieht man sich die Formulierungen noch einmal an, so muss man aber feststellen, dass eigentlich nicht der Streit durch die Vorlage der Traditionsnotiz entschieden wurde, sondern hier lediglich gemeint sein dürfte, dass die ältere auf den Todfall geschlossene Schenkung nach dem Tod des Tradenten gleichsam gemäß der schriftlichen Aufzeichnung schlagend wird. ${ }^{52}$ Von einer Anerkennung als Beweismittel kann also keine Rede sein. Die Nachfahren ließen sich von der Traditionsnotiz bezeichnenderweise auch nicht beeindrucken und haben die ältere Schenkung beeinsprucht. Oswald Redlich wiederum hat darauf hingewiesen, dass Traditionsbücher vereinzelt ergänzend und neben den Zeugen zur Feststellung eines

46 Siehe zum Folgenden zum Teil bereits Zehetmayer, R.: Urkunden, S. 66-85.

47 Zehetmayer, R.: Urkunden, S. 67.

48 Siehe etwa Reichert, Folker: Landesherrschaft, Adel und Vogtei. Zur Vorgeschichte des spätmittelalterlichen Ständestaates im Herzogtum Österreich. Beihefte zum Archiv für Kulturgeschichte 23. Köln - Wien 1985; Zehetmayer, Roman: Advocati und defensores. Die adeligen Neben- und Untervögte der steirischen Klöster im 12. und 13. Jahrhundert. In: Handschriften, Historiographie und Recht. Winfried Stelzer zum 60. Geburtstag. Hg. von G. Pfeifer. MIÖG, Ergänzungsband 42. Wien - München 2002, S. 225-254.

49 Zehetmayer, R.: Urkunden, S. 19-25, 34-39, 67.

50 Wild, J.: Traditionsnotizen, S. 477f.

51 Siehe oben S. 23.

52 Wie Anm. 23. 
Sachverhalts herangezogen wurden. Aber auch die von ihm vorgebrachten Stellen meinen zumindest zum Teil offenbar lediglich, dass die Zeugen gemäß den Einträgen der Traditionsbücher ausgesagt hätten. Jedenfalls wurden letztere in diesen Beispielen immer nur ergänzend beigezogen.$^{53}$ Auch bleiben solche Fälle ganz selten.

Aufschlussreich sind nicht zuletzt jene Fälle, bei denen es wegen einer in Traditionsnotizen festgehaltenen Schenkung zum Streit vor Gericht kam. Als Beispiel sei ein Rechtsstreit zwischen dem Passauer Bischof und der Zisterze Baumgartenberg aus der Mitte des 12. Jahrhunderts vorgebracht. Das Stift legte dem zur Streitschlichtung delegierten Abt von Ebrach zwar ein in diesem Zusammenhang stehendes, das Stift begünstigende, in Form einer Notitia niedergeschriebenes ${ }^{54}$ Testament des Gründers vor, ${ }^{55}$ doch war selbst der Zisterze klar, damit vor dem Forum nicht durchzudringen, so dass von vorneherein Adelige mitgebracht wurden, die den Inhalt durch Zeugenaussagen bestätigen konnten. ${ }^{56}$ Ähnliches geschah bei einem Konflikt zwischen dem Stift Garsten und einem Adeligen. Als dieser eine von einem Standesgenossen durch Traditionsnotiz schriftlich

53 Redlich, O.: Privaturkunde, S. 86f.

54 Zehetmayer, R.: Urkunde, S. 103f.

55 Niederösterreichisches Urkundenbuch (= NÖUB) II. 1078-1158. Edd. R. Zehetmayer - D. Weltin - M. Weltin, M. unter Mitarbeit von G. Marian und C. Mochty-Weltin. Publikationen des Instituts für Österreichische Geschichtsforschung 8/2. St. Pölten 2013, Nr. 273 (1148). Das Testament weist auch keine Zeugen auf, so dass es sich um eine Art Gedächtnisprotokoll handeln dürfte. Siehe dazu auch Zehetmayer, Roman: Probleme um die Anfänge der geistlichen Siegelurkunde in der Babenbergermark. In: Urkunden - Schriften - Lebensordnungen. Neue Beiträge zur Mediävistik. Hg. von A. Schwarcz - K. Kaska. Veröffentlichungen des Instituts für Österreichische Geschichtsforschung 63. Wien 2015, S. 251-271, hier S. $253 f$.

56 NÖUB II, Nr. 274: Quod scimus, loquimur, et quod vidimus, hoc testamur. Scimus et vidimus bone memorie Ottonem virum nobilem duorum claustrorum fuisse fundatorem: alterius Cisterciensis ordinis, alterius Regularium Canonicorum. Sed claustrum Regularium amplioribus diviciis ditavit collatis ad idem beneficiis, que ab episcopo Patauiense habuit. Cuius eciam privilegio eadem beneficia conmunivit, sed instante illi mortis articulo nobis presentibus, accito fratre suo Walchuno aliisque personis nobilibus honestis et veracibus, conmisit nobis omnia mobilia sua inter duo predicta cenobia dividenda sub ea tamen caucione, ut, si episcopus Pataviensis diminueret bona claustro Regularium a suo predecessore collata, omnia tam predia quam mobilia nostre forent ecclesie. Facta hac et firmata omnium rerum testamento suarum donacione manus suas inter manus nostras conpositis Domino Christo sese nudum obtulit, promittens de reliquo vite sue tempore modum et formam vivendi sub precepto nostro se velle custodire. Norunt hec domnus Eberhardus Salisburgensis episcopus, Heinricus dux Bawarie et multi comites et viri nobiles ac religiosi abbates et prepositi. Predicto igitur Ottone viam universe carnis ingresso episcopus Patauiensis bona per antecessorem suum prefato cenobio Regularium tradita usibus suis mancipavit et, ut res sub predicta condicione nobis conmissas cum Regularibus divideremus, a nobis instanter exigere cepit. Cum ergo ad causam hanc dirimendam abbas Ebracensis a Cysterciensi capitulo dispositus advenisset, episcopus offerebat assercionis sue testimonia, quod nulla condicione interposita bona illa mobilia duobus iamdictis cenobiis fuerint destinata. Nos vero econtra testamentum morte testatoris confirmatum et nobilium personarum testimonium de illa donacione, que ab ipso donatore novissimum spiritum fuerat dictata, ad confirmandam assercionis nostre partem parati sumus exhibere. Sed cum abbas Ebracensis testimonium episcopi contra nos vellet recipere, ipsum deprecati sumus, quatenus ad examen sanctorum patrum Cysterciensis capituli terminanda differetur summa tocius negocii. Quo nobis non concesso denuo ei suggessimus, ne consensu suo vel presencie sue auctoritate iusiurandum testium episcopi roboraret, utpote qui nec de visis nec auditis falso iuraturi essent. Preterea episcopo per fratrem nostrum mandavimus, ut saltem pro reverencia domini pape ab iniusta testium produccione cessaret. [...]. Accepto autem mandato per litteras apostolicas Saltzburgensis archiepiscopus ad prosequendam causam nostram Patauiensem episcopum evocavit necnon et eos, qui supremo et extremo interfuerunt testamento Ottonis viri nobilis, de cuius rebus videbatur esse contencio. Cumque assistente ei domino Romano Gurcense episcopo testes accitos, viros nobiles ac veraces, de visis et auditis sub iureiurando dicere paratos paratus esset audire, [...]. 
festgehaltene Schenkung an Garsten beeinspruchte, konnte das Kloster nicht einfach diese Notitia als Beweismittel vorlegen, sondern musste erst der Tradent erscheinen, um öffentlich eine entsprechende Aussage zu tätigen. ${ }^{57}$ Auch bei den lang andauernden und detailliert dokumentierten Auseinandersetzungen zwischen dem Stift Reichersberg und einem Adeligen um Münsteuer spielten Traditionsnotizen als Beweismittel keine Rolle. ${ }^{58}$

Es gibt demnach keinen verwertbaren Beleg, dass Notitien entscheidenden Einfluss auf die Urteilsfindung vor Gericht gehabt hätten und als Beweismittel anerkannt worden wären. Stattdessen gibt es nicht wenige Quellenstellen, wonach auch bei Vorhandensein einer Traditionsnotiz alleine die Zeugen vom Richter konsultiert wurden. Auch sonst gibt es deutliche Hinweise, dass sich Adelige von Traditionsnotizen nicht haben beeindrucken lassen, haben sie doch immer wieder frühere Schenkungen beeinsprucht oder ignoriert. ${ }^{59}$

Gegen eine Beweiskraft von Traditionsnotizen vor Gericht spricht auch das im Vergleich mit den Siegelurkunden seltene Vorkommen von gefälschten Notitien, ${ }^{60}$ das mit der Unmöglichkeit zusammenhängt, vor Gericht so einen entscheidenden Rechtsvorteil zu erreichen.

Was aber hat es mit dem Verb allegare auf sich, dem wie gesehen Joachim Wild eine große Bedeutung zugemessen hat? Dazu ist zunächst festzuhalten, dass dieses Verb in Traditionsnotizen gar nicht selten vorkommt. Sieht man sich die entsprechenden Formulierungen und den Zusammenhang genauer an, so zeigt sich freilich, dass allegare zumeist eher die allgemeine Bedeutung von „übergeben“ zukommt, jedenfalls daraus in keinem Fall irgendein Hinweis auf das Eintragen des Rechtsgeschäfts in ein öffentlich anerkanntes Buch abgeleitet werden muss. ${ }^{61}$

Nur in jenen Gebieten, in denen sich in weiterer Folge Notariatsinstrumente durchgesetzt haben, wie Südtirol, konnte Traditionsbücher ab der Mitte des 13. Jahrhunderts sekundär eine „amtliche Beweiskraft“ zugesprochen werden. ${ }^{62}$ Sonst aber bleibt es dabei: es gibt es keinerlei Hinweise auf eine allgemeine Anerkennung von Traditionskodizes als öffentliches Buch und von Klöstern als glaubwürdige Orte durch den Adel in Österreich.

Nicht auszuschließen ist lediglich, dass Traditionsnotizen bei außergerichtlichen Streitschlichtungen eine gewisse Rolle spielten. So beeinflusste vielleicht die Vorlage

57 NÖUB III. 1156-1182. Ed. R. Zehetmayer unter Mitarbeit von M. Gneiß - S. Lessacher - G. Marian - C. Mochty-Weltin - D. Weltin. Publikationen des Instituts für Österreichische Geschichtsforschung 8/3. St. Pölten 2017, Nr. $7^{22}$.

58 Siehe etwa Hecht, A.: Überlegungen, S. 111; Classen Peter: Der Prozeß um Münsteuer (1154-76) und die Regalienlehre Gerhochs von Reichersberg. ZRG, Germanistische Abteilung 77, 1960, S. 324-345.

59 Siehe etwa Zehetmayer, R.: Urkunde, S. 68f., über einen Bericht in der nach 1181 in Salzburg beziehungsweise Admont entstandenen ,jüngeren Vita Gebehardi archiepiscopi“. Erzbischof Konrad I. (1106-1147) fand nämlich Traditionsnotizen oder ein Heft über inzwischen entfremdete Schenkungen seiner Vorgänger an Admont. Konrad versuchte nun, diese Güter für Admont zurückzuerlangen, doch zeigt sich in weiterer Folge, dass sich die betroffenen Adeligen davon mitnichten beeindrucken ließen.

60 Zehetmayer, R.: Urkunde, S. 67.

61 Ebd. S. $67 f$.

62 Redlich. O.: Privaturkunde, S. 88. 
einer Notitia im Zuge einer Vermittlung Markgraf Leopold III., der nun bereit war, einen entfremdeten Besitz dem Stift St. Peter zurückzugeben. ${ }^{63}$ Unter Umständen konnten bei solchen streitschlichtenden Versammlungen Notitien einem Streitgegner von Nutzen sein und haben sich manche Adelige tatsächlich durch die Vorlage von Schriftstücken überzeugen lassen, im Unrecht zu sein. Aber das war im Grunde lediglich eine mehr oder weniger freiwillige Bereitschaft. Ob dies häufiger der Fall war, muss mangels weiterer Belege für unseren Untersuchungsraum ohnehin offen bleiben.$^{64}$

Noch eine weitere Differenzierung muss getroffen werden. In einer Traditionsnotiz des Stiftes Michaelbeuern über einen Grundstückkauf des Abtes, der damit die Begehung eines Jahrtages finanzieren wollte, steht, dass er die Niederschrift veranlasste, damit dieser Jahrtag im Kloster weiterhin beachtet werden würde. ${ }^{65}$ Auf den ersten Blick scheint es, als ob hier ein Hinweis vorläge, dass Traditionsnotizen doch Rechtskraft zugemessen wurde. Allerdings war dies offenbar hier nur bei den Konventualen innerhalb des Klosters der Fall und es wurde keinesfalls damit gerechnet, dass die Niederschrift auch vor Gericht beweiskräftig sein würde. ${ }^{66}$ Dass Traditionsnotizen innerhalb eines Klosters oder der klösterlichen Grundherrschaft auch sonst sehr wohl Rechtskraft zugekommen sein wird, ist ohnehin naheliegend, weil die den Sachverhalt niederschreibende Institution zugleich den Richter in der Angelegenheit stellte.

Dass sich die geistlichen Empfänger durch die Niederschrift von Traditionsnotizen und -büchern sehr wohl mitunter darüber hinausgehende Rechtssicherung erhofften, geht etwa aus manchen Vorreden von Traditionsbüchern hervor. So heißt es in der Vorrede eines Göttweiger Traditionsbuches, dass Personen, die Schenkungen nicht anerkennen, durch den Inhalt der Traditionsnotizen überzeugt werden mögen. ${ }^{67}$ In diese

63 NÖUB II, Nr. $5^{3}$ (1131/1136). Nach einer verbalen Invocatio wird eine Traditionsnotiz inseriert, aus der die Rechte des Klosters hervorgehen. Es folgt: Contigit autem post hec, ut eadem possessio multis intervenientibus impedimentis maxime propter remotionem loci distracta et imminuta ex maiori parte a predicto altari alienata esset, donec huius rei veritas divino et humano ventilata consilio amatoribus veritatis claruit Cinnrado videlicet venerabili Salzburgensis ecclesie archiepiscopo, Romano Curcensi episcopo et marchioni Livpoldo multisque aliis personis probabilibus. Ammonitus itaque prędictus marchio divino instinctu et sano consilio archiepiscopi Cůnradi aliorumque deum timentium, sicut iustus, sicut misericors et totus deo devotus, [...] que distracta erant [...] reassignavit. Zu bedenken ist, dass die Handlung bereits beinahe 100 Jahre zurücklag, so dass keine Zeugen mehr aufzutreiben gewesen wären. In solchen Fällen zeigte sich die Begrenztheit des Zeugenbeweises. Die Inserierung der Traditionsnotiz beweist, dass diese bei der Streitschlichtung bei der Hand war und legt nahe, dass sie dabei eine Rolle spielte; siehe dazu bereits Zehetmayer, R.: Urkunde, S. 69f.

64 Vereinzelte in diese Richtung gehende Hinweise von außerhalb des Untersuchungsraums finden sich bei Redlich, O.: Privaturkunden, S. $85 \mathrm{f}$.

65 NÖUB III, Nr. 14 ${ }^{18}$ : Hanc autem vineam dominus Waltherus Bvrensis abbas idcirco prefato precio distracto comparavit, quatinus post obitum suum fratribus sui monasterii de eadem vinea in anniversario depositionis sui singulis annis in refectorio vino et ceteris necessariis habundanter serviatur. Sed et hanc inscriptionem idcirco fieri duxit necessario, quatinus hoc in perpetuum in Bvrensi cenobio stabile esset et nulli abbatum succedentium hoc institutum licet mutare.

66 Siehe bereits Mitis, O.: Urkundenwesen, S. 64. Siehe auch Dienst, H.: Regionalgeschichte, S. 111.

67 Traditionsbücher Göttweig, S. 143f.: Diffinitio operis sequentis. De diversa fidelium conlatione iste libellus est conscriptus, qui pro remedio anime sue privatim vel publice propria nobis largiti sunt bona, que idcirco scriptis assignavimus, ut, si quis eadem in posterum retrahere nititur, evidenti testimonio convincatur. Nunc enim tantis inveteratus est mundus malis, ut quod plures pro spe mercedis ęterne conferunt ecclesie, alii iusticie obliti non metuunt diripere. Non autem solummodo a potentibus et nobilibus, sed etiam ab infimis iste locus in variis expensis adcrevisse 
Richtung weisen auch einige Formulierungen in Traditionsnotizen selbst. So steht in einer Traditionsnotiz des Stiftes Heiligenkreuz, dass ein adeliger Tradent seine Schenkung verschriftlicht haben wollte, damit seine Nachfahren dies sehen und seinen Willen nicht beeinträchtigen würden ${ }^{68}$ Aber auch dies gibt doch nur einen Wunsch wieder. Weder im Göttweiger noch im Heiligenkreuzer Material findet sich irgendein Hinweis, dass sich Adelige durch die Vorlage von Traditionsnotizen in ihrem Verhalten haben beeinflussen lassen. Andere Formulierungen zeigen sogar, wo die Grenzen der Rechtssicherheit lagen und wie sich die Empfänger konkret eine Verbesserung erhofften. In einer Michaelbeuerner Traditionsnotiz etwa wird in einer Art Corroboratio festgehalten, dass zur Absicherung der Übereignung die Erinnerung der Zeugen und an das Geschriebene fortdauern soll. ${ }^{69}$ Hier steht demnach die Erinnerung im Vordergrund, und eindeutig wird auf die Funktion der Traditionsnotiz als Gedächtnishilfe hingewiesen.

Kurz sei abschließend noch einmal auf einige bereits vorgestellte, von der Forschung als grundsätzlich rechtsverbessernd angesehene Maßnahmen zurückgekommen: zunächst zur Verknüpfung der in Traditionsbüchern festgehaltenen Rechtsgeschäfte mit der Stiftermemoria. ${ }^{70}$ Die als Gegenleistung für eine Schenkung geforderte Gebetsleistung mag zuweilen tatsächlich die Rechtssicherheit erhöht haben, denn es ist durchaus denkbar, dass sich etwa Familienangehörige aus Pietät gegenüber dem Schenker oder aus religiösen Gründen bei Vorlage des Traditionsbuchs mit dem Eintrag über die Stiftung der Vorfahren von einer Anfechtung abhalten ließen, um die Gebetsleistung nicht zu gefährden. Belegt kann dies für Österreich aber nicht werden, dagegen finden sich zahlreiche Beispiele von Konflikten der Klöster mit Verwandten, ${ }^{71}$ die sich davon offenbar auch von der Memoria bzw. den ausbedungenen Gebeten nicht haben abhalten lassen. Da aber jene Fälle nirgends dokumentiert sind, bei denen im Vorfeld von Konflikten die Memoria Einfluss auf das Verhalten adeliger Streitparteien ausübte oder es gar nicht

dinoscitur, quorum omnium singularis invenitur beate memorie domnus noster Altmannvs Patauiensis episcopus, apostolice sedis legatus, qui huius loci extitit fundator strenuissimus. Denique hunc locum, qui vocatur mons Kotwigensis, a solitudine edificans Deo famulantibus habitabilem reddidit ac amenum et monasterium construens in honore sancte Dei genitricis perpetue virginis Marie dedicavit fratribusque regulariter coadunatis, plura, quibus pre sua necessitudine carere poterat, in prediis et in aliis donariis subministravit. Precipue vero de beneficiis militum suorum, que in eius potestatem iustis ex causis devenerant vel qui absque herede vita excesserant, contradidit, quod infra scriptum melius declarabitur. Has autem omnes traditiones quas fecit, partim testimonio tam spiritalium quam secularium personarum, partim episcopali auctoritate firmavit. Siehe auch Dienst, H.: Regionalgeschichte, S. 111 mit Anm. 28.

68 NÖUB III, Nr. 18²2: Hoc autem monimentum voluit conscribi, ut illud filii filiorum suorum aspicerent et voluntati suce minime contrairent.

69 NÖUB III, Nr. 14²2: Verum ne delegatio premissa irrita posthac habeatur, testium in posteros et litterarum memoria perennuatur.

70 Dazu und zum Folgenden mit der Literatur Zehetmayer, R.; Urkunde, S. 73f.

71 Siehe zum Beispiel Die Traditionsurkunden des Klosters Garsten: Ed. S. Haider. Quelleneditionen des Instituts für Österreichische Geschichtsforschung 8. Wien - München 2011, Nr. T 175 (1182-1192): Notum sit universis [...], qualiter quoddam predium [...] a quodam Arnoldo [...] conparavimus, cuius defuncto successit hęres filius suus Rídolf [...] Hic cupiditate rerum ductus anime patris sui oblitus [...]. Das Kloster betont, dass der Sohn das „Vermächtnis“ des Vaters missachtete. Dass so die „Memoria“ an den Vater beeinträchtigt wird, beeindruckte den Sohn aber nicht. 
erst zu Anfechtungen kam, kann die Wirkung der Gebetsleistungen nicht eingeschätzt werden. ${ }^{72}$

Fraglich bleibt auch, ob die erwähnte Offen- oder Landeskundigkeit jene rechtliche Wirkung entfalten konnte, die etwa Heinrich Fichtenau angenommen hat. ${ }^{73}$ Dass eine möglichst breite Öffentlichkeit vom Rechtsgeschäft in Kenntnis gesetzt wurde und ein größerer, über die eigentlichen Handlungszeugen hinausgehender Kreis für die Rechtsfindung herangezogen werden konnte, ist naheliegend und war zweifellos ein wichtiger weiterführender Gedanke. ${ }^{74} \mathrm{Zu}$ überlegen wäre aber, in welchem Ausmaß es in dem von mündlicher Tradition geprägten adeligen Rechtsleben nicht öffentliche, aber dennoch vor Gericht einklagbare Rechtsgeschäfte überhaupt geben konnte. Im Liegenschaftsverkehr war ein nicht öffentlich geschlossener Vertrag jedenfalls kaum vorstellbar, da der Besitz an Grund und Boden nicht geheim bleiben konnte und rechtliche Ansprüche vor Gericht nicht durchsetzbar gewesen wären. ${ }^{75}$ Zweifellos erhöhte die Offenkundigkeit die Rechtssicherheit eines mündlich geschlossenen Vertrags, nicht zuletzt weil so auch nach dem Tode der Handlungszeugen Personen zur Verfügung standen, die um den Sachverhalt Bescheid wussten. ${ }^{76} \mathrm{Zu}$ bedenken ist aber, dass auch diese Personen ähnlich wie Zeugen bewusst oder unbewusst Falschaussagen tätigen konnten. Denn wer hätte sich Details von all den im Laufe von Jahrzehnten landeskundig gewordenen Rechtsgeschäften merken können? Am ehesten Verwandte oder die Besitznachbarn, doch gerade diese verfolgten oft ihre eigenen Interessen und waren keine Garanten für die korrekte Wiedergabe des Rechtszustandes. Die Offenkundigkeit konnte zwar die Rechtskontinuität und -sicherheit erhöhen, ein gewisses Risiko blieb aber, denn je größer der zeitliche Abstand zur Handlung wurde, umso mehr stieg die Gefahr von Irrtümern und Manipulationen. Zu wenig beachtet wurde von der Forschung vielleicht zudem, dass die

72 Jedenfalls gibt es keinen Hinweis, dass sich vor Gericht die Streitparteien auf Traditionsnotizen bzw. -kodizes aufgrund von deren mutmaßlicher Memorialfunktion berufen hätten. Zu bedenken ist, dass man die Zeugen weglassen hätte können, falls man alleine auf die Memorialfunktion vertraut hätte. Ähnliches trifft auch auf die Androhung geistlicher Strafen in den Traditionen zu (etwa Codex traditionum Claustroneoburgensis, Nr. 122, 124, 142). Auch diese könnten in dem einen oder anderen Fall die Bereitschaft, das Rechtsgeschäft einzuhalten, erhöht haben, nachweisen dürfte es sich für unseren Untersuchungsraum aber nicht lassen.

73 Dazu und zum Folgenden mit der Literatur Zehetmayer, R.; Urkunde, S. 62-64.

74 Dass der Wunsch auf mündliche Weitergabe des Handlungsablaufs tatsächlich eine Rolle spielte, zeigt sich etwa bei Formulierungen einiger Publicationes, die das zum Ausdruck bringen; etwa Salzburger Urkundenbuch 1, S. 309 Nr. 123: Omnes filii hominum narrent filiis suis ut memoriter teneant, quod [...]; Mitis O.: Urkundenwesen, S. 13f. Anm. 4.

75 Fichtenau, Forschungen, S. 306, ging davon aus, dass bei Rechtsgeschäften „kleiner Leute“ untereinander der Gedanke der Öffentlichkeit nicht immer gegeben war. Möglich wäre, dass der Kreis der darüber Bescheid Wissenden ein kleinerer war, doch waren auch hier vor allem nicht öffentliche Liegenschaftsabkommen kaum denkbar. Für Klöster kamen nicht öffentlich geschlossene Gütergeschäfte ohnehin kaum in Frage, da ihnen noch dazu weitgehend die Mittel fehlten, den Bruch von Geheimverträgen zu belangen.

76 So zeigt ein Beispiel, dass verschiedene Personen auch noch über ein Jahrhundert nach der Pfarrerhebung über die damals festgelegten Grenzen Bescheid wussten; Urkunden der Benedictiner-Abtei zum hl. Lambert in Altenburg. Ed. H. Burger. Fontes rerum Austriacarum II/21. Wien 1865, Nr. 2 (1200-1204); siehe auch Dienst, H.: Babenberger-Studien, S. 10. 
Offenkundigkeit grundsätzlich nur die Rechtskontinuität der mündlich geschlossenen Verträge verlängerte, aber nicht die Rechtskraft der Traditionsnotizen selbst, wie dies wie erläutert im gewissen Sinne Fichtenau angenommen hat.

Ähnliche Fragen ergeben sich auch bei der von Hagen Keller vorgebrachten Meinung, dass die bei Vertragsabschluss vorgenommenen symbolischen Handlungen eine „Verbindlichkeit und dauerhafte Geltung im kollektiven Gedächtnis “ hergestellt hätten. ${ }^{77}$ Denn wie konkret sollten Symbole eine längerfristige Rechtssicherung garantieren? Konnten solche Symbole nicht lediglich erreichen, dass sich die Anwesenden an das Ereignis besser erinnern und vielleicht an die Einhaltung in einem erhöhten Ausmaß gebunden fühlen würden?

Da trotz aller Bemühungen nicht belegt werden kann, dass Traditionsnotizen vor Gericht als Beweismittel Anerkennung gefunden haben, wird man in ihnen zusammenfassend betrachtet wie bereits die ältere Forschung in erster Linie Erinnerungsbehelfe für mündlich geschlossene Verträge sehen müssen, wenn auch die Offenkundigkeit die Rechtskontinuität über den Zeugenbeweis hinaus zumindest eine Zeit lang wahren konnte und die Vorlage einer vielleicht noch mit einer Gebetsleistung verknüpften Notitia bei den einen oder anderen Adeligen die Bereitschaft, ein Rechtsgeschäft einzuhalten, erhöht haben mag. ${ }^{78}$

Warum aber haben dann österreichische Klöster und Adelige solange an Traditionsnotizen bzw. mündlich geschlossenen Verträgen festgehalten und so zögerlich Siegelurkunden selbst ausgestellt, nämlich erst seit etwa 1200, obwohl die Bischöfe von Passau oder die Babenberger dies bereits seit fast 100 Jahren taten $^{79}$ ? Gründe dafür waren wohl

77 Siehe S. 25.

78 Diese 2010 vom Verfasser vorgebrachte Meinung (Zehetmayer, R.: Urkunde) hat Zustimmung (etwa Härtel, R.: Urkunden, S. 112), von Siegfried Haider aber auch Kritik erfahren. In einer ausführlichen Rezension hält er fest, dass er nicht an eine eingeschränkte Rechtswirksamkeit der Traditionsbücher glaube, zumal sich in „Traditionsbüchern vereinzelt auch Aufzeichnungen rechtlicher Entscheidungen“ fänden; Haider, Siegfried: Rezension Zehetmayer, Urkunde und Adel. Jahrbuch des Oberösterreichischen Musealvereines. Gesellschaft für Landeskunde 156, 2011, S. 219-224, hier S. 221. In einem 2015 erschienenen Aufsatz gesteht er in nochmaliger Auseinandersetzung mit dem 2010 erschienenen Buch dann aber doch zu, dass Traditionsnotizen vor Gericht nicht als Beweismittel dienen konnten, obwohl sie über eine kirchlich-sakrale Autorität verfügt hätten. Die Klöster seien jedenfalls von der Beweiskraft ihrer Traditionsnotizen und -bücher überzeugt gewesen. Als Hinweis dafür erachtet Haider, dass bei der Niederschrift von Konflikten die dem Streit zugrunde liegende bzw. vorangegangene Schenkung noch einmal erwähnt oder abgeschrieben wird (Haider, S.: Streitfälle, S. 221f.). Dieses Argument leuchtet aber nicht ganz ein, denn darin kann wohl kein Beleg für eine Rechtskraft der älteren Traditionsnotizen gesehen werden, da so nur der Sachverhalt aus Sicht der Klöster dargelegt werden sollte und als Gedächtnisstütze dienen konnte. Haider spricht sich ebd. S. 222 Anm. 67 gegen eine vom Verfasser dieser Zeilen angeblich getroffene Unterscheidung der Rechtsqualität von Traditionsnotizen über Rechtsgeschäfte zwischen Adeligen und Klöstern einerseits und Adeligen untereinander andererseits aus. Nach Haider habe Zehetmayer nur zwischen Adeligen geschlossenen Rechtsgeschäften Beweiskraft zuerkannt. Dies beruht allerdings auf einem Missverständnis, denn im 2010 erschienenen Buch ist eine unterschiedliche Rechtskraft nirgends postuliert worden. 
nicht zuletzt das Festhalten an Gewohnheiten oder die vielleicht vielfach als hinreichend angesehen Ersitzungsfristen, die nach dem Tode der letzten Handlungszeugen in der Regel wohl bereits schlagend geworden sind ${ }^{80}$. Dazu kommt, dass vor der Rezeption des gelehrten Rechts Siegel an Privaturkunden per se vor Gericht wohl noch kein Beweismittel darstellten, sondern ihre rechtliche Wirkung in einem hohen Ausmaß von der Autorität des Siegelführers abhängig war ${ }^{81}$. Zwar stellten Mönche in Göttweig oder Melk bereits in den 1120er und 1130er Jahren, und damit kurz nach dem Aufkommen von privaten Siegelurkunden, im österreichischen Raum Fälschungen her, doch beruhte auch bei diesen die Wirkung vermutlich zu einem guten Teil eher auf der Autorität der Siegelführer ${ }^{82}$. Dass Siegelurkunden im Unterschied zu Traditionsnotizen gefälscht wurden, noch dazu so früh, weist indes nichtsdestotrotz auf einen ihnen zumindest von den Fälschern zugemessenen „rechtlichen Mehrwert“.

\section{K průkaznosti tradičních záznamů v prostoru Rakouska}

V posledních letech byla rakouskými a bavorskými diplomatiky velmi kontroverzně řešena otázka, zda tradiční záznamy disponovaly veřejně akceptovanou právní a důkazní silou. Starší bádání (především Oswald Redlich a Oskar Mitis) tradičním záznamům jako takovým žádnou důkazní sílu nepřiznávalo. Ta měla spočívat výlučně na výpovědích svědků, pročež nejdůležitější funkcí tradičních záznamů měla být písemná fixace jmen svědků a obsahu právního jednání. Pro právní kontinuitu po smrti svědků byla důležitá veřejná proklamace právního jednání, které díky ní vešlo v obecné povědomí. Heinrich Fichtenau šel o krok dále a domníval se, že také tradiční záznamy samy o sobě mohly vytvářet právní kontinuitu, nebot předčítáním skutkové podstaty bylo uchováno obecné povědomí o právním jednání a pamět na toto jednání. Fichtenau v samotném sepsání tradičního záznamu spatřoval nástroj, jímž byla vytvářena obecná známost o dané věci, a proto přisuzoval tradičním záznamům charakter právní záruky. Bavorští diplomatikové jako Heinrich Wanderwitz a především Joachim Wild konečně zastávali mínění, že tradiční záznamy lze považovat za „objektivní, na stranách nezávislá zlistinění“ s právní silou, přičemž spatřovali paralely s Gesta municipalia.

Proti tomu je však možné namítnout, že například šlechtici nechávali právní pořízení uzavřená mezi sebou jen zřídka zanášet do tradičních knih, kterým očividně nepřisuzovali téměř žádný úřední charakter; snad i proto, že kláštery nevnímali jako neutrální místa. Především ale chybí jakékoliv použitelné doklady pro to, že by tradiční záznamy získaly rozhodující vliv při nalézání rozsudků před soudem a byly zde uznávány jako důkazní prostředky. Místo toho lze nalézt nemálo dokladů pro to, že i při existenci tradičního záznamu byli soudcem konzultováni svědkové. A existují i další zřetelné náznaky toho, že se šlechtici tradičními záznamy nenechali př́liš ovlivnit, když si stále znovu nárokovali nebo ignorovali předchozí donace. Proti důkazní síle tradičních záznamů před

80 Ders.: Urkunde, S. 83-85.

81 Siehe zuletzt Zehetmayer, Roman: Funktion und Rechtskraft der besiegelten Privaturkunde im Reich bis zur Jahrtausendwende. Deutsches Archiv 69, 2013, S. 503-513, hier S. 527, 529; Zehetmayer, R.: Probleme, S. 262, 269. 
soudem hovoří i fakt, že na rozdíl od zpečetěných listin existuje u tradičních záznamů jen málo falz, což jistě souvisí s nemožností, dosáhnout s pomocí takové písemnosti před soudem rozhodující výhodu. Tradiční záznamy mohly nabýt právní sílu jen v rámci klášterního velkostatku, a to zejména tehdy, když instituce, která právní jednání sepsala, v téže věci zároveň ustanovovala soudce.

Celkově lze v tradičních záznamech spatřovat v prvé řadě pamětovou oporu pro ústně uzavřené smlouvy, přestože alespoň zpočátku právní kontinuitu mohla vedle svědků zajištovat i „obecná známost" právního jednání.

Proč ale kláštery a šlechtici tak dlouho trvali na ústně uzavřených smlouvách a tak zdrženlivě vydávali zpečetěné listiny? V neposlední řadě to zřejmě vyplývalo ze lpění na zvyklostech, ale také z existence vydržecích lhůt, které většinou přišly na řadu po smrti posledních svědků a byly vnímány jako dostačující. Především však také z toho, že před recepcí učeného práva pečeti na listinách samy o sobě nepředstavovaly žádný důkazní prostředek a jejich právní síla se do značné míry odvozovala $\mathrm{z}$ autority pečetitele.

Z faktu, že zpečetěné listiny byly již ve 20. a 30. letech 12. století - tzn. brzy po vzniku soukromých zpečetěných listin - falšovány, vyplývá, že jim byla přinejmenším ze strany falzátorů přisuzována vyšší právní hodnota. 
